\title{
Neurobehavioral conditions and effects of gender, weight and severity in preterm infants according to the Neonatal Behavioral Assessment Scale
}

\author{
Alicia Alvarez-Garcia ${ }^{1 *}$, Albert Fornieles-Deu ${ }^{2}$, Carme Costas-Moragas ${ }^{1}$ and Francesc Botet-Mussons ${ }^{3}$ \\ ${ }^{1}$ Clinical and Health Psychology Department. Universitat Autònoma de Barcelona, 08193 Bellaterra (Cerdanyola del Vallès) (Spain). \\ ${ }^{2}$ Psychobiology and Methodology of the Health Sciences Department. Universitat Autònoma de Barcelona. (Spain). \\ ${ }^{3}$ Hospital Clinic de Barcelona. Universitat de Barcelona. (Spain).
}

\begin{abstract}
Título: Efecto del sexo, peso y gravedad de la prematuridad en el neurocomportamiento de recién nacidos prematuros a través de la Neonatal Behavioral Assessment Scale.

Resumen: El aumento de los recién nacidos prematuros en los últimos años hace que se incremente el interés por estudiar las consecuencias de este factor de riesgo. En este trabajo se evalúan 30 prematuros (a las 40 semanas de edad gestacional) con la Escala para la Evaluación del Comportamiento Neonatal de Brazelton y se comparan sus resultados con los de un grupo control formado por 28 neonatos a término. Así mismo se comparan dentro del grupo de prematuros el efecto del peso, el sexo y la gravedad de la prematuridad.

Los controles muestran superioridad en 9 de los 28 ítems comportamentales de la Escala y en dos de las 5 categorías. Los prematuros muestran superioridad en Habituación. Las niñas muestran mejor ejecución en la categoría Social-Interactiva.

Los prematuros se ven afectados por la abrupta interrupción de su maduración intrauterina. Aunque podría haber un efecto de aprendizaje debido a la exposición extrauterina.

Palabras clave: Neonatal Behavioral Assessment Scale; NBAS; prematuridad; neuroconducta neonatal; evaluación desarrollo neonatal.
\end{abstract}

\section{Introduction}

Breakthroughs in the field of medicine have reduced some perinatal risk factors. However, some of these, such as prematurity, have not changed or even increased. Prematurity is considered to occur when birth takes place before 37 weeks of gestational age (GA) and is currently one of the main perinatal risk factors in the field of neonatology, due to the immaturity of the fetus at birth. Improvements in obstetrics and pharmacological techniques in recent years have made it possible for the number of surviving premature babies to reach a prevalence of 7\% in Spain (National Institute of Statistics, 2012). As a consequence of the rising number of premature babies, interest in this population group has also increased.

Some studies carried out using image diagnosis techniques (MRI, PET) have documented abnormalities in white-matter and gray-matter of the brain (Seme-Ciglenecki, 2007; Woodward, Anderson, Austin, Howard, \& Inder, 2006), high risk of cerebellar, brain or thalamic lesions, cortex sub development, and reduced caudate nucleus volume (Newsham, Knox, \& Cooke, 2007). The decrease in the size of the cerebral region, and more specifically of the parietal and temporal regions, is related with neurobehavioral dysfunction, impaired working memory and early neurodevelopment delay (Soria-Pastor et al., 2009). All these handicaps

* Dirección para correspondencia [Correspondence address]: Alicia Alvarez-Garcia. E-mail: alicia.alvarez@,copc.cat
Abstract: The increasing number of preterm babies in recent years has raised interest in studying the consequences of prematurity as a risk factor. In the present paper, 30 preterm babies (at 40 weeks of gestational age) were assessed using the Neonatal Behavioral Assessment Scale and the results were compared with those of a control group of 28 full term babies. Moreover, the influence of weight, sex and gestational age was analyzed considering the Brazelton results in the preterm group.

The preterm group showed significantly lower scores than the control group for 9 of the 28 behavioral items in the Scale and for 2 of the 5 clusters. However, preterm babies performed better in habituation to disturbing stimuli (light and noise) during sleep. In relation to the influence of sex, premature girls performed better in the Social-Interactive cluster.

The preterm group has lower neurobehavioral conditions than the full term group, probably due to the abrupt interruption of their intrauterine maturation. In contrast, they showed a better ability of habituation, maybe as a consequence of a learning effect due to earlier additional extrauterine exposition.

Key words: Neonatal Behavioral Assessment Scale; NBAS; prematurity; neonatal neurobehavior; neonatal development assessment.

are also associated with poorer psychomotor skills and even cerebral palsy (Davis, Ford, Anderson, \& Doyle, 2007).

Other research has focused on the study of the preterm infant during childhood and has revealed a high risk of mild or severe disability at 5 years of age (Ohgi et al., 2003), cognitive and motor delay at 2 years of age (Spinillo et al., 2009), developmental coordination disorder at 8 years of age (Davis et al., 2007), and even the tendency to develop specific disorders such as autism (Limperopoulos et al., 2008).

Most of the above referenced studies have analyzed the behavior of extreme or high risk premature neonates $(<32$ weeks of GA), studies of moderate or low risk preterm babies (from 32 to 36 weeks of GA) being scarce. These latter studies reveal that the low risk preterm baby also shows neurologic deficits, for example, reductions in several brain areas correlated with the IQ at 9 years of chronological age (Soria-Pastor et al., 2009). The explanation, as Feldman \& Eidelman (2003) established, is grounded in the critical importance of the last gestational period (from 32 to 37 weeks) for the maturation of the vagal tone and circadian systems, owing to cortical maturation, synaptic growth and rapid myelinisation. The same authors showed that the maturation rate from 33 to 35 weeks GA was found to predict schoolage outcomes in preterm children.

In the research of preterm babies, another aspect to take into account is low birth-weight (LBW) as a variable that can affect development. A baby whose birth-weight is lower than percentile 10 is considered small for gestational age (SGA) (de Bernabé et al., 2004). Prematurity and SGA are two different situations that have one aspect in common: 
low birth-weight. However, prematurity implies being born before time and, in consequence, organism immaturity, while SGA is related with a deficit in the nutritional process during gestation (Jiménez, Figueras, Villanueva \& Botet, 1982; Figueras et al., 2008; Cloherty et al., 2005). Many studies have analyzed LBW but neglected the GA or indistinctly used LBW and prematurity (Davis et al., 2007; Ohgi et al., 2003). Other research has demonstrated that the LBW, per se, taken separately from prematurity, is also a risk factor and has highlighted that SGA full term babies perform worse in neurobehavioral tests than neonates of an adequate birthweight (Costas-Moragas, 2009; Figueras et al., 2009).

At the beginning of a study of neonatal behavior, another variable to consider is gender, due to it having been demonstrated that male babies are more sensitive to perinatal risks than females (Spinillo et al., 2009). Being male implies performing more poorly in neurobehavioral tests and subsequently evolving more poorly too (Canals, FernándezBallart, \& Esparó, 2003; Lundqvist \& Sabel, 2000; BoatellaCosta, Costas-Moragas, Botet-Mussons, Fornieles-Deu \& De Cáceres-Zurita, 2006). Furthermore, being male increases the risk of neuronal damage, with areas related to balance and motor skills being particularly vulnerable (Davis et al., 2007). More specifically, the increase in abnormal outcomes of neuronal development is 1.93 times higher in boys than in girls (Spinillo et al., 2009).

One of the hardest tasks for clinicians working with preterm babies is the identification of subjects with a high risk of neuroevolutive deficit. In this regard, the Neonatal Behavioral Assessment Scale (NBAS) (Brazelton \& Nugent, 2011) assesses the adaptative and interactive dimensions of neonate behavior and describes its neurobehavioral outcomes. It can be used for both assessment and early intervention (Nugent, Petrauskas, \& Brazelton, 2009) and has been revealed to be a useful test for predicting the risk of later developmental disabilities in high risk neonates (CostasMoragas, 2009; Ohgi et al., 2003), to detect differences between healthy newborns (Boatella-Costa, 2007; Canals et al., 2003; Lundqvist \& Sabel, 2000), and also to examine the effects of pre- and perinatal risk factors on neonate neuronal development (Rao et al., 2007; Spinillo et al., 2009).

The aim of the present study is to examine the behavior of preterm newborns in comparison with that of full term newborns using the NBAS. To do this, neurobehavioral outcomes have been assessed in preterm babies when they were about to be born (at 40 weeks of GA) and the results are compared with those of full term newborns.

This research has a second goal, to discern whether the preterm group shows differences in neurobehavioral performance related to:

- Birth-weight (normal or low for GA)

- Sex

- Gestational age (extreme or moderate prematurity)

This study represents the first step in a longer term study of behavioral characteristics in relation to potential neurobe- havioral repercussion, and will form the basis for planning interventions and preventing or minimizing deficits in the group of preterm newborns.

\section{Method}

\section{Participants}

The subjects were newborns at less than 37 weeks of GA, who were admitted to the NICU at Hospital Clinic, Barcelona, Spain. The control group included infants born at the same hospital during the same period, who were of adequate weight and whose GA was greater than 37 weeks. The mothers in both groups were volunteers who gave birth at Hospital Clinic. Patients admitted to this hospital are mostly of middle and lower-middle social class and are covered by the Spanish National Health Service.

The subjects with the following conditions were excluded: infant newborns or mothers that showed any kind of disease (physical or mental, neither intraventricular hemorrhage nor hypoxic ischemic insult), cases where it was not possible to carry out the assessment of neonatal behavior in the adequate conditions, and cases where the parents refused to collaborate with the research. There were 30 preterm babies (study group) and 28 full term babies (control); only the study group was used for the second goal. It was considered moderate preterm babies with a GA from 32 to 36 weeks and extreme those with a GA lower than 32 weeks. And the babies whose birth-weight is lower than percentile 10 is considered small for gestational age (SGA) [11]. See Table 1 for description.

Table 1. Quantitative variables of sample.

\begin{tabular}{cccccc}
\multirow{2}{*}{ Gender } & & \multicolumn{2}{c}{ Gestational age weeks/days } & \multicolumn{2}{c}{ Weight in grams } \\
\cline { 2 - 6 } Male & & Control & Preterm & Control & Preterm \\
& $\bar{X}$ & $39: 34$ & $30: 83$ & 3158.42 & 1222.47 \\
& $N$ & 19 & 15 & 19 & 15 \\
& $S D$ & 0.997 & 1.771 & 370.102 & 277.652 \\
\hline Female & $\bar{X}$ & $39: 64$ & $30: 70$ & 3463.64 & 1353.07 \\
& $N$ & 11 & 15 & 11 & 15 \\
& $S D$ & .924 & 2.765 & 451.071 & 449.186 \\
\hline Total & $\bar{X}$ & $39: 45$ & $30: 76$ & 3270.33 & 1287.77 \\
& $N$ & 30 & 30 & 30 & 30 \\
& $S D$ & .966 & 2.282 & 421.377 & 372.871 \\
\hline
\end{tabular}

\section{Clinical Data Collection}

Obstetric and neonatal data was collected using a document including the following information:

- Clinical and obstetric history of the mother, containing family data such as origin of the parents, mother's drug habits, her previous pregnancies, her diseases and her activity during the pregnancy period. 
- Clinical history of the infant to obtain information about characteristics of the birth and the immediate neonatal period.

\section{NBAS assessment}

All newborns were evaluated using the Spanish version of the Neonatal Behavioral Assessment Scale (NBAS) 3rd edition (Brazelton \& Nugent, 1997), which combines issues dealing with reflex responses and the behavioral repertoire of the infant. The NBAS assesses abilities to cope and adaptative strategies. It is an interactive assessment that is currently considered to be the most sensitive instrument for the detection of behavioral competences in neonates. The Scale consists of 35 items for the assessment of behavior: 28 general, 7 supplementary (especially appropriated for the assessment of risk neonates) and 16 reflex responses. Most behavioral items, 27, are scored on a 9-point scale where 9 is a high functioning level. An additional item, number of smiles, is scored by frequency of responses. The 8 remaining items are scored on a curvilinear scale, where the central score is high functioning, and are rescored as linear on a 5, 6 or 8-point scale. Each item level implies a different response; numbers are not associated with answer intensity. The reflex responses are scored on a 4-point scale where 2 is normal. NBAS does not give a sum score but a map of scores that describes the neurobehavioral organization of the newborn.

In order to compare the evaluations of infant behavior, items have been grouped into clusters describing global functions that have been obtained through a factorial analysis using a group of neonates in our ambit (Costas-Moragas, Fornieles-Deu, Botet-Mussons, Boatella-Costa \& de Cáceres-Zurita, 2007). These clusters have shown more reliability and internal consistency than the clusters proposed in the NBAS manual and include the supplementary items. The clusters are:

- Autonomic Nervous System (ANS) / Motor Performance: concerning the infant's ability to make homeostatic adjustments in relation with the instability of the ANS, and the quality of movement and tone ( 9 items).

- Habituation: concerning the neonate's ability to respond or inhibit discrete stimuli during sleep (4 items).

- State Organization: concerning the infant's ability to organize him/herself to respond to stimuli, paying attention to the time he/she needs to react (5 items).
- State Regulation: concerning the neonate's resources to console him/herself and self-recover after a state of maximum excitation (6 items).

- Social-Interactive: concerning the quality of alert responsiveness and the ability to attend to visual and auditory stimulus (6 items).

- Reflexes: records the number of abnormal reflex responses (16 items).

States of consciousness are observed and recorded throughout the entire administration of the test. Six levels are considered: 1-deep sleep, 2-active sleep, 3-drowsy, 4quiet alert, 5-active alert, and 6-crying. Measures of individual items were rescored and the sum score for each cluster was calculated.

\section{Procedure}

The study was approved by the Investigational and Ethics Committee of the Hospital Clínic, Barcelona and informed consent was obtained from parents. The preterm newborns were assessed at 40 weeks of GA and full term babies were assessed in the first 3 days after birth.

Examinations were carried out by an examiner accredited by The Brazelton Institute (Harvard Medical School, Boston) in the hospital's neonatology unit. All newborns were evaluated under standard conditions: the newborn must be between two feedings, in a calm, quiet, semi-dark room, and with the temperature between $25-26^{\circ} \mathrm{C}$.

\section{Statistical analyses}

Quantitative variables of the sample were analyzed by comparing independent groups using a Student t-test. Qualitative variables were compared using a $\chi 2$ test. We considered a result significant when $\mathrm{P}$ was $\leq .05$. The statistical analysis was carried out using SPSS 19 (IBM SPSS Inc., 2011).

\section{Results}

Table 2 summarizes the results of the Student t-test mean comparisons. The comparisons have been made item by item between both groups (control and preterm). 
Table 2. Mean, standard deviation $(S D)$, and Student t-test comparison.

\begin{tabular}{|c|c|c|c|c|}
\hline & Control & Preterm & Student $t$ & Signif. $(p)$ \\
\hline & $\bar{X} \pm S D$ & $\bar{X} \pm S D$ & & \\
\hline Response Decrement Light & $5.61 \pm 3.70$ & $7.61 \pm 1.37$ & $-2.69^{54}$ & .010 \\
\hline Response Decrement Rattle & $6.70 \pm 2.76$ & $7.89 \pm 1.20$ & $-2.09^{53}$ & .042 \\
\hline Response Decrement Bell & $4.35 \pm 3.96$ & $7.50 \pm 3.08$ & -3.0446 & .004 \\
\hline Res. Decr. Tactile Stim. Foot & $6.96 \pm 2.01$ & $5.77 \pm 1.53$ & 2.3443 & .024 \\
\hline Orientation Animate Visual & $4.81 \pm 1.98$ & $4.25 \pm 1.69$ & $1.14^{51}$ & .26 \\
\hline Or. Animate Visual-Auditory & $6.27 \pm 1.14$ & $5.87 \pm 1.99$ & $.90^{52}$ & .37 \\
\hline Or. Inanimate Visual & $4.73 \pm 2.29$ & $5.07 \pm 1.96$ & $.60^{49}$ & .56 \\
\hline Or.Inanimate Visual-Auditory & $6.18 \pm 1.68$ & $6.40 \pm 1.92$ & .4756 & .64 \\
\hline Or. Animate Auditory & $8.48 \pm .79$ & $7.87 \pm 1.59$ & $1.88^{57}$ & .07 \\
\hline Or. Inanimate Auditory & $6.93 \pm 1.53$ & $6.53 \pm 1.80$ & $.92^{56}$ & .36 \\
\hline Alertness & $6.23 \pm 1.68$ & $6.67 \pm 1.88$ & -.9457 & .35 \\
\hline General Tone & $4.77 \pm .77$ & $4.97 \pm .85$ & $-.95^{57}$ & .35 \\
\hline Motor Maturity & $6.13 \pm .43$ & $6.50 \pm .57$ & $-2.80^{58}$ & .007 \\
\hline Pull-to-sit & $4.83 \pm 2.49$ & $5.83 \pm 2.22$ & $-1.62^{57}$ & .11 \\
\hline Defensive Movements & $5.84 \pm 1.91$ & $5.57 \pm 2.19$ & $.48^{51}$ & .64 \\
\hline Activity Level & $4.87 \pm .51$ & $4.80 \pm .48$ & $.52^{58}$ & .61 \\
\hline Peak of Excitement & $3.50 \pm .63$ & $3.73 \pm .64$ & $-1.42^{58}$ & .16 \\
\hline Rapidity of Build-up & $2.77 \pm 1.57$ & $1.60 \pm 1.40$ & 3.0457 & .004 \\
\hline Irritability & $5.17 \pm 1.56$ & $3.67 \pm 1.97$ & $3.25^{57}$ & .002 \\
\hline Lability of State & $3.67 \pm 1.56$ & $1.83 \pm 1.44$ & $4.73^{58}$ & $<.001$ \\
\hline Cuddliness & $6.53 \pm .94$ & $6.50 \pm 1.08$ & $.13^{57}$ & .90 \\
\hline Consolability & $6.32 \pm 1.49$ & $4.80 \pm .45$ & $2.21^{22}$ & .038 \\
\hline Self-Quieting & $2.35 \pm 1.90$ & $3.78 \pm 3.27$ & -1.4927 & .15 \\
\hline Hand-to-Mouth & $3.93 \pm 2.45$ & $1.67 \pm 1.67$ & $4.19^{58}$ & $<.0001$ \\
\hline Tremulousness & $6.90 \pm 2.75$ & $3.17 \pm 2.73$ & $5.28^{58}$ & $<.0001$ \\
\hline Startles & $8.48 \pm 1.62$ & $3.93 \pm 2.90$ & $7.41^{57}$ & $<.0001$ \\
\hline Lability of Skin Color & $5.93 \pm .26$ & $5.37 \pm .49$ & 5.3956 & $<.0001$ \\
\hline Smiles & $0.34 \pm .81$ & $1.36 \pm .93$ & $-3.48^{23}$ & .002 \\
\hline Quality of Alertness & $5.97 \pm 1.63$ & $5.80 \pm 1.67$ & $.39^{58}$ & .70 \\
\hline Cost of Attention & $6.77 \pm 1.61$ & $7.33 \pm 1.42$ & -1.4457 & .15 \\
\hline Examiner Facilitation & $6.07 \pm 1.72$ & $6.83 \pm 1.34$ & $-1.93^{55}$ & .06 \\
\hline General Irritability & $6.20 \pm 1.63$ & $7.40 \pm 1.33$ & $-3.13^{58}$ & .003 \\
\hline Robustness and Endurance & $6.43 \pm 1.76$ & $7.23 \pm 1.61$ & -1.8456 & .071 \\
\hline State Regulation & $7.00 \pm .91$ & $6.90 \pm 1.32$ & .3451 & .734 \\
\hline Examiner's Emotional Resp. & $7.53 \pm .78$ & $7.70 \pm .92$ & $-.76^{56}$ & .450 \\
\hline
\end{tabular}

As can be seen, the control group shows superiority (it scores better for 9 items). However, it must be noted that the preterm group scored better for 5 items. Three of these belong to the Habituation cluster, where a decreasing response to a disturbing stimulus (light, bell and rattle) is measured.
Table 3. Comparison of results by clusters.

\begin{tabular}{|c|c|c|c|}
\hline \multirow[t]{2}{*}{ 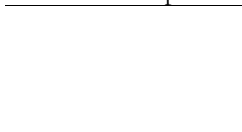 } & \multicolumn{2}{|c|}{ Punctuations, $\bar{X} \pm S D$} & \multirow[t]{2}{*}{ Signif. $(p)$} \\
\hline & $\begin{array}{l}\text { Control } \\
(N=28)\end{array}$ & $\begin{array}{l}\text { Preterm } \\
(N=30)\end{array}$ & \\
\hline $\begin{array}{l}\text { ANS/Motor } \\
\text { mance }\end{array}$ & Perfor- $6.28 \pm .67$ & $5.23 \pm .83$ & $<.0001$ \\
\hline Habituation & $5.06 \pm 2.44$ & $6.24 \pm 1.90$ & .046 \\
\hline State Organization & $3.99 \pm .92$ & $3.49 \pm .88$ & .037 \\
\hline State Regulation & $4.91 \pm .76$ & $4.53 \pm .79$ & .07 \\
\hline Social-Interactive & $5.96 \pm 1.36$ & $5.99 \pm 1.28$ & .93 \\
\hline
\end{tabular}


Table 3 shows the same results as Table 2 but here they have been grouped into clusters. Better performance by the full term newborns can be observed for ANS/Motor, and for State Organization, while the preterm infants perform better in Habituation (as noted in the individual items analysis).

Table 4. Comparison in the preterm group by gender, weight and gestational age (GA).

\begin{tabular}{|c|c|c|c|c|c|c|}
\hline & & $\begin{array}{l}\text { ANS/ Motor Performance } \\
\bar{X} \pm S D\end{array}$ & $\begin{array}{l}\text { Habituation } \\
\bar{X} \pm S D\end{array}$ & $\begin{array}{c}\text { Range of State } \\
\bar{X} \pm S D\end{array}$ & $\begin{array}{c}\text { State Regulation } \\
\bar{X} \pm S D\end{array}$ & $\begin{array}{c}\text { Social-Interactive } \\
X \pm S D\end{array}$ \\
\hline \multirow[t]{2}{*}{ Sex } & Female $(N=15)$ & $5.47 \pm .72$ & $6.60 \pm 1.26$ & $3.63 \pm 1.05$ & $4.79 \pm .81$ & $6.76 \pm .86^{*}$ \\
\hline & Male $(N=15)$ & $4.98 \pm .88$ & $5.88 \pm 2.36$ & $3.33 \pm .69$ & $4.27 \pm .71$ & $5.23 \pm 1.19$ \\
\hline \multirow[t]{2}{*}{ Weight } & Adequate $(N=21)$ & $5.28 \pm .89$ & $6.07 \pm 2.05$ & $3.50 \pm .71$ & $4.61 \pm .86$ & $6.05 \pm 1.24$ \\
\hline & Small $(N=9)$ & $5.11 \pm .70$ & $6.63 \pm 1.53$ & $3.44 \pm 1.26$ & $4.33 \pm .61$ & $5.86 \pm 1.45$ \\
\hline \multirow[t]{2}{*}{$\overline{\mathrm{GA}}$} & Moderate $(N=7)$ & $5.07 \pm .72$ & $6.18 \pm 1.76$ & $3.20 \pm .58$ & $4.45 \pm .37$ & $5.69 \pm .64$ \\
\hline & Extreme $(N=23)$ & $5.27 \pm .87$ & $6.26 \pm 1.97$ & $3.57 \pm .95$ & $4.55 \pm .89$ & $6.09 \pm 1.42$ \\
\hline
\end{tabular}

* significant $\mathrm{P} \leq .01$.

Table 4 shows the results of the study of the influence of the three risk factors referenced in the introduction. These results have been grouped into clusters.

In relation to sex, better performance of preterm girls in the Social-Interactive and specific items of other clusters is noted: Activity level $(t=3.578, p=.002$; IC $95 \%=.223$ .844), Quality of alertness ( $t=2.078, p=0.047$; IC $95 \%=.017$ - 2.383), State Regulation $(t=2.205, p=0.041$; IC 95\% $=.047$ - 1.953) and Examiner's Emotional Response $(t=2.361, p$ $=.029$; IC $95 \%=.082-1.384)$. However, in the item by item comparison, boys perform better in the Response Decrement Bell $(t=-2.244, p=0.044$; IC 95\% $=-4.627--.074)$.

Concerning weight depending on GA (adequate or low) no significant differences have been revealed in the cluster comparison but in the items of Response Decrement Light $(t=(24.676)-2.078 ; p=.048$; IC 95\% $=-1.881--.008)$ and General Tone $(t=(18.417)-2.102 ; p=.05$; IC $95 \%=-$ 1.309- -.001), scores for adequate weight preterm babies are better.

Finally, no significant differences were observed when GA is analyzed in the preterm group, either in clusters or item by item.

\section{Discussion}

The results show that, in accordance with a previous study (Costas-Moragas, 2009), the preterm group has obtained lower scores than the full term group, assessed using the NBAS. In our results, the control group is significantly superior in 9 of the 34 items of the scale (Table 2). However, it should be emphasized that the preterm group has a better score in the Habituation cluster (Tables 2 and 3) and in the items of motor maturity and general irritability (Table 2). Forcada et al. (2000) reported similar results. They argued that this better behavior of preterm babies is due to the experience acquired during exposure to the extrauterine space, during which period they would have developed a habituation mechanism to the visual and auditory stimuli. Nonetheless, other authors have presented data against this learning effect when auditory stimuli are used (Bisiacchi, Mento, \& Suppiej, 2009). In view of these conflicting results, it will be necessary to carry out additional studies in the future to answer this question.

An interesting point to light is that in the item of decrement response of tactile foot stimulation (also Habituation cluster, Table 2) the preterm newborns scored significantly worse than the full term newborns. This finding is not observed in any other study. Infants that are lengthy hospitalized, as preterm infants, show a greater sensitivity to pain compared to full term infants (Grunau, 2006). This author state that multiple components of the NICU experience probably interact producing a negative impact, in this case they are more sensitive to pain as well to uncomfortable tactile stimuli and so they have a worse decrement to them.

Concerning differences in neurobehavioral outcome by sex found in the preterm group (Table 4), the results of this study agree with those found by Boatella-Costa et al. (2007) in their study of full term newborns. In our study, girls scored significantly better in the Social-Interactive cluster and in more items. These differences are therefore more remarkable in preterm than in full term babies and may be due to the sex effect being accentuated by the prematurity (it is known that the neurologic evolution of the brain is different for both genres (Kelly, Ostrowski, \& Wilson, 1999)). These findings agree with those obtained by Spinillo et al. (2009), who demonstrates that preterm male fetuses have an inherently greater risk baseline than females for adverse neurodevelopmental outcomes, although this susceptibility varies across the categories of obstetric risk factors.

In relation to the data obtained in the comparison by weight (Table 4), our results show an absence of significant differences, which disagrees, in general, with those of the previous studies that suggested poorer performance by babies that are small for their gestational age (SGA)) (Davis et al., 2007; de Bernabé et al., 2004). A deficient state organization and regulation was found in SGA newborns, suggesting a delay in neurological maturation) (Figueras et al., 2009). However, this discrepancy must be qualified, because significant differences have been found in two items (Response Decrement Light and General Tone), confirming the worse performance of SGA newborns.

With regard to the comparison by GA (Table 4), and as opposed to what would be expected in the light of previous 
research (Soria Pastor et al., 2009), no significant differences supporting a deficit of one group versus the other have been found. Nonetheless these opposing results must be established more solidly (in our study the sample size is moderate).

Finally, it must be noted that the SES has not been considered a contaminant factor because Spinillo et al. (2009) demonstrated that in this developmental period SES does not yet have any influence.

To summarize, results obtained in this research confirm that preterm newborns have poorer behavioral competencies than full term babies. These differences can be explained by the causes of early birth in preterm babies being an abrupt alteration of the madurative processes and involving a deficit in their neurodevelopment.

The better scores obtained by preterm babies for habituation to a disturbing stimuli are evidence that these newborns are exposed (in the NICU) to visual and auditory stimuli at a very early age. Although the organism reacts using this mechanism, it is very likely to be harmful. This idea leads us to emphasize the importance of early intervention in order to improve the environment to which babies are exposed, and to make it as becoming as possible.

We have found differences by sex and weight, which leads us to consider that further and broader studies are

\section{References}

Bisiacchi, P. S., Mento, G., \& Suppiej, A. (2009) Cortical auditory processing in preterm newborns: an ERP study. Biological Psychology, 82 (2), 176-185. doi: 10.1016/j.bbr.2011.03.031

Brazelton, T. \& Nugent, B. (1997) Escala para la Evaluación del Comportamiento Neonatal, $3^{a}$ Ed., España: Paidos Iberica.

Brazelton, T. \& Nugent, B. (2011) Neonatal Behavioral Assessment Scale, 4th Ed., Hoboken, NJ US: John Wiley \& Sons Inc.

Boatella-Costa, E., Costas-Moragas, C., Botet-Mussons, F., Fornieles-Deu, A., \& De Cáceres-Zurita, M. L. (2007). Behavioral gender differences in the neonatal period according to the Brazelton scale. Early Human Development, 83 (2), 91-97. doi: 10.1016/j.earlhumdev.2006.05.006

Canals, J., Fernández-Ballart, J., \& Esparó, G. (2003). Evolution of neonatal behavior assessment scale scores in the first month life. Infant Behavior \& Development, 26 (2), 227-237. doi: 10.1016/S0163-6383(03)00019-5

Cloherty, J., Eichenwald, E., \& Stark, A. (2005). Manual de cuidados neonatales, $4^{a}$ Ed., Barcelona (España): Massons.

Costas-Moragas, C. (2009). Perinatal factors influencing development: Spain. In K. J. Nugent, B. J. Petrauskas, T. B. Brazelton, K. J. Nugent, B. J. Petrauskas, \& T. B. Brazelton (Eds.), The newborn as a person: Enabling bealthy infant development worldwide. (pp. 41-50). Hoboken, NJ US: John Wiley \& Sons Inc.

Costas-Moragas, C., Fornieles-Deu, A., Botet-Mussons, F., Boatella-Costa, E., \& de Cáceres Zurita, M. L. (2007). Evaluación psicométrica de la escala de brazelton en una muestra de recién nacidos españoles. Psicothema, 19 (1), 140-149.

Davis, N. M., Ford, G. W., Anderson, P. J., Doyle, L. W., \& Victorian Infant Collaborative Study Group. (2007). Developmental coordination disorder at 8 years of age in a regional cohort of extremely-low-birthweight or very preterm infants. Developmental Medicine and Child Neurology, 49 (5), 325-330. doi:10.1111/j.1469-8749.2007.00325.x

Feldman, R., \& Eidelman, A. I. (2003) Skin-to-skin contact (Kangaroo Care) accelerates autonomic and neurobehavioural maturation in preterm infants. Developmental medicine and child neurology, 45 (4), 274-281. doi: 10.1017/S0012162203000525

Figueras, F., Meler, E., Iraola, A., Eixarch, E., Coll, O., Figueras, J., et al. (2008). Customized birthweight standards for a spanish population. Eu- needed to ascertain the same. Regarding sex, it can be said that being male tends to imply poorer behavioral competencies, related to social interaction. This predisposition may be accentuated by prematurity. At the same time, weight seems to exert some influence on the neurobehavioral outcomes shown by the preterm. Our data reveal a direct association between SGA and performance, performance being worse the lower weight for $G A$ is.

\section{Conclusions}

The main contributions of this research are to present the map of neurobehavioral deficits of the preterm population and to demonstrate that prematurity aggravates the inherent risks of other factors, such as sex or weight.

Further research is needed into the learning effect and how the period in the Neonatal Intensive Care Unit affects preterm babies. All these data could help explain how preterm newborns can benefit from early intervention (in order to minimize deficits in their neurodevelopment).

Acknowledgements.- This study was partially supported by a grant from the Ministerio de Ciencia e Innovación of the Spanish Government (PSI2010-18193).

ropean Journal of Obstetrics \& Gynecology and Reproductive Biology, 136(1), 20 24. doi: 10.1016/j.ejogrb.2006.12.015

Figueras, F., Oros, D., Cruz-Martinez, R., Padilla, N., Hernandez-Andrade, E., Botet-Musson, F., \& Gratacos, E. (2009) Neurobehavior in Term, Small-for-Gestational Age Infants With Normal Placental Function. Pediatrics, 124, e934-e941. doi: 10.1542/peds.2008-3346

Forcada, M., Muller-Nix, C., Fumeaux, P., Pierrehumbert, B., Moessinger, A., \& Ansermet, F. (2000) Neonatal behavior and parental representations of the preterm infant. Infant Mental Health Journal, 4-5 (Special Issue) $7^{\text {th }}$ Congress World Association for Infant Mental Health. Abstract n.111.

Grunau, R. E. (2006). Long-term consequences of pain in human neonates. Seminars in Fetal\&Neonatal Medicine, 11 (4), 268-275. doi: 10.1016/j.siny.2006.02.007

IBM SPSS Inc. M. J. Norusis (2011): IBM SPSS Statistics 19 Guide to Data Analysis. Chicago: SPSS INC.

Instituto Nacional de Estadística (2012). Madrid: INE Retrieved from

http: / / www.ine.es $/$ jaxi/tabla.do?type=pcaxis\&path $=/$ t20 $/$ e301 $/$ nacim /a2008/10/\&file=01010.px

Jiménez, R., Figueras, J., Villanueva, C., \& Botet, F.. (1982) Valoración del crecimiento intrauterino a nivel del mar, entre las 25 y 43 semanas de edad gestacional. Archivos de Pediatría, 33, 191-200.

Kelly, S. J., Ostrowski, N. L., \& Wilson, M. A. (1999) Gender differences in brain and behavior: hormonal and neural bases. Pharmacology Biochemistry and Behavior, 64, 655-664. doi: 10.1016/S0091-3057(99)00167-7

Limperopoulos, C., Bassan, H., Sullivan, N. R., Soul, J. S., Robertson, R. L.Jr, Moore, M., et al. (2008). Positive screening for autism in expreterm infants: Prevalence and risk factors. Pediatrics, 121(4), 758-765. doi: $10.1542 /$ peds.2007-2158

Lundqvist, C., \& Sabel, K. (2000). Brief report: The brazelton neonatal behavioral assessment scale detects differences among newborn infants of optimal health. Journal of Pediatric Psychology, 25(8), 577-582. doi: 10.1093/jpepsy/25.8.577

Newsham, D., Knox, P. C., \& Cooke, R. W. (2007). Oculomotor control in children who were born very prematurely. Investigative Ophthalmology \& Visual Science, 48(6), 2595-2601. doi: 10.1167/iovs.06-1425 
Nugent, K., Petrauskas, B., \& Brazelton T. (2009). The newborn as a person: Enabling healthy infant development worldwide. Hoboken, NJ US: John Wiley \& Sons Inc.

Ohgi, S., Arisawa, K., Takahashi, T., Kusumoto, T., Goto, Y., Akiyama, T., et al. (2003). Neonatal behavioral assessment scale as a predictor of later developmental disabilities of low birth-weight and/or premature infants. Brain \& Development, 25(5), 313-321. doi: 10.1016/S03877604(02)00233-4

Rao, R., Sampers, J. S., Kronsberg, S. S., Brown, J. V., Desai, N. S., \& Anand, K. J. (2007). Neurobehavior of preterm infants at 36 weeks postconception as a function of morphine analgesia. American Journal of Perinatology, 24(9), 511-517. doi: 10.1055/s-2007-986675

Seme-Ciglenecki, P. (2007). Predictive values of cranial ultrasound and assessment of general movements for neurological development of preterm infants in the maribor region of slovenia. Wiener Klinische Wochenschrift, 119(15-16), 490-496. doi: 10.1007/s00508-007-0839-7

Spinillo, A., Montanari, L., Gardella, B., Roccio, M., Stronati, M., \& Fazzi, E. (2009). Infant sex, obstetric risk factors, and 2-year neurodevelopmental outcome among preterm infants. Developmental Medicine \& Child Neurology, 51(7), 518-525. doi: 10.1111/dmcn.2009.51.issue-7

Soria-Pastor, S., Padilla, N., Zubiaurre-Elorza, L., Ibarretxe-Bilbao, N., Autor, Falcon, C., Bargallo, N., Mercader, J. M., \& Junqué, C. (2009). Decreased Regional Brain Volume and Cognitive Impairment in Preterm Children at Low Risk. Pediatrics, 124, e1161-e1170. doi: 10.1542/peds.2009-0244

Valero de Bernabé, J., Soriano, T., Albaladejo, R., Juarranz, M., Calle, M. E., Martínez, D., et al. (2004). Risk factors for low birth weight: A review. European Journal of Obstetrics \& Gynecology and Reproductive Biology, 116(1), 3-15. doi: 10.1016/j.ejogrb.2004.03.007

Woodward, L. J., Anderson, P. J., Austin, N. C., Howard, K., \& Inder, T. E. (2006). Neonatal MRI to predict neurodevelopmental outcomes in preterm infants. The New England Journal of Medicine, 355(7), 685-694. doi: 10.1056/NEJMoa053792

(Article received: 05-03-2013; revised: 01-06-2013; accepted: 03-06-2014) 